\title{
Spotlight on measles 2010: Ongoing measles outbreak in Northern Ireland following an imported case, September-October 2010
}

R Smithson (richard.smithson@hscni.net) ${ }^{1}$, N Irvine ${ }^{1}$, C Hutton ${ }^{1}$, L Doherty ${ }^{1}$, A Watt ${ }^{2}$

1. Health Protection Service, Public Health Agency, Belfast, Northern Ireland

2. Regional Virology Service, Royal Victoria Hospital, Belfast, Northern Ireland

We report an ongoing outbreak of measles with five laboratory-confirmed and four epidemiologically linked cases in Northern Ireland as at 26 October 2010. The index case was an unvaccinated non-Northern Ireland resident with subsequent genotyping suggesting that infection originated in the usual country of residence of this case. Confirmed cases include one patient with a history of two measles-mumps-rubella vaccine doses.

Measles is a statutorily notifiable disease on the basis of clinical suspicion in Northern Ireland under the Public Health Act [1]. Although measles vaccine was first introduced in Northern Ireland in 1968, it was not until the combined measles-mumps-rubella (MMR) vaccine was introduced in 1988 at the age of 15 months that transmission was significantly interrupted. In response to the United Kingdom (UK) seroprevalence surveys, a vaccination campaign with measles-rubella vaccine was implemented for all school age children in 1994. This campaign achieved high uptake. A second dose of MMR was introduced in 1996 at the age of 3-4 years. As elsewhere in the UK, MMR uptake in Northern Ireland declined as a result of the controversy surrounding the alleged link between the MMR vaccine and autism and inflammatory bowel disease. However, uptake rates in Northern Ireland have remained above those for the UK overall, and have now recovered to $92.4 \%$ when measured at the age of 24 months (Figure 1), and $97.1 \%$ for the first dose and $92.2 \%$ for two doses at the age of five years (Figure 2) $[2,3]$.

From a peak of 12,647 cases in 1961, an average of 65 cases have been notified annually in Northern Ireland from 2000 to 2008 . However only six of these cases were laboratory-confirmed in this period, with only one documented as a result of transmission within Northern Ireland. Between December 2009 and March 2010, 24 cases associated with the Irish Traveller community were reported. Sixteen of these were laboratory-confirmed. All occurred in unvaccinated children and young adults (median age seven years, range three months -23 years) and involved two different $D_{4}$ genotypes. This occurred against the background of the ongoing outbreak of measles mainly affecting the Traveller community in the Republic of Ireland [4].

This is now the second outbreak to have been identified this year, following the report of the index case on 17 September 2010. As at 26 October, an additional four laboratory-confirmed cases and four epidemiologically linked cases have been reported. One confirmed case has had two MMR vaccine doses. The median age of cases is 19 years, the range is $12-24$ years. Two of the cases have required hospitalisation. This outbreak is not linked with the Irish Traveller community.

A case is defined as laboratory-confirmed when, in the absence of a history of recent vaccination, a clinically suspected case has either a positive measles IgM result in blood or oral fluid, or a positive measles RNA detection. A case is defined as epidemiologically linked when a clinically suspected case has, within 7-18 days of onset of symptoms, been in contact with a laboratory-confirmed case during the infectious period.

\section{Outbreak description}

The index case was an unvaccinated young adult who arrived in Northern Ireland on 3 September 2010 from another European country, where ongoing measles outbreaks had been previously reported, to work as a volunteer in a youth organisation. The onset of symptoms was 12 September and the case was notified on 17 September. The diagnosis was laboratory-confirmed by PCR detection, with $\mathrm{D}_{4}$ genotype subsequently identified.

The second case, also laboratory-confirmed, was reported on 1 October in another unvaccinated volunteer with the same youth organisation, who had had direct contact with the index case. Onset of symptoms was 28 September. This case had attended a weekend event organised by the youth organisation on 25-26 


\section{FIGURE 1}

Measles-mumps-rubella vaccination uptake rate at the age of 24 months, Northern Ireland, 1999-2010

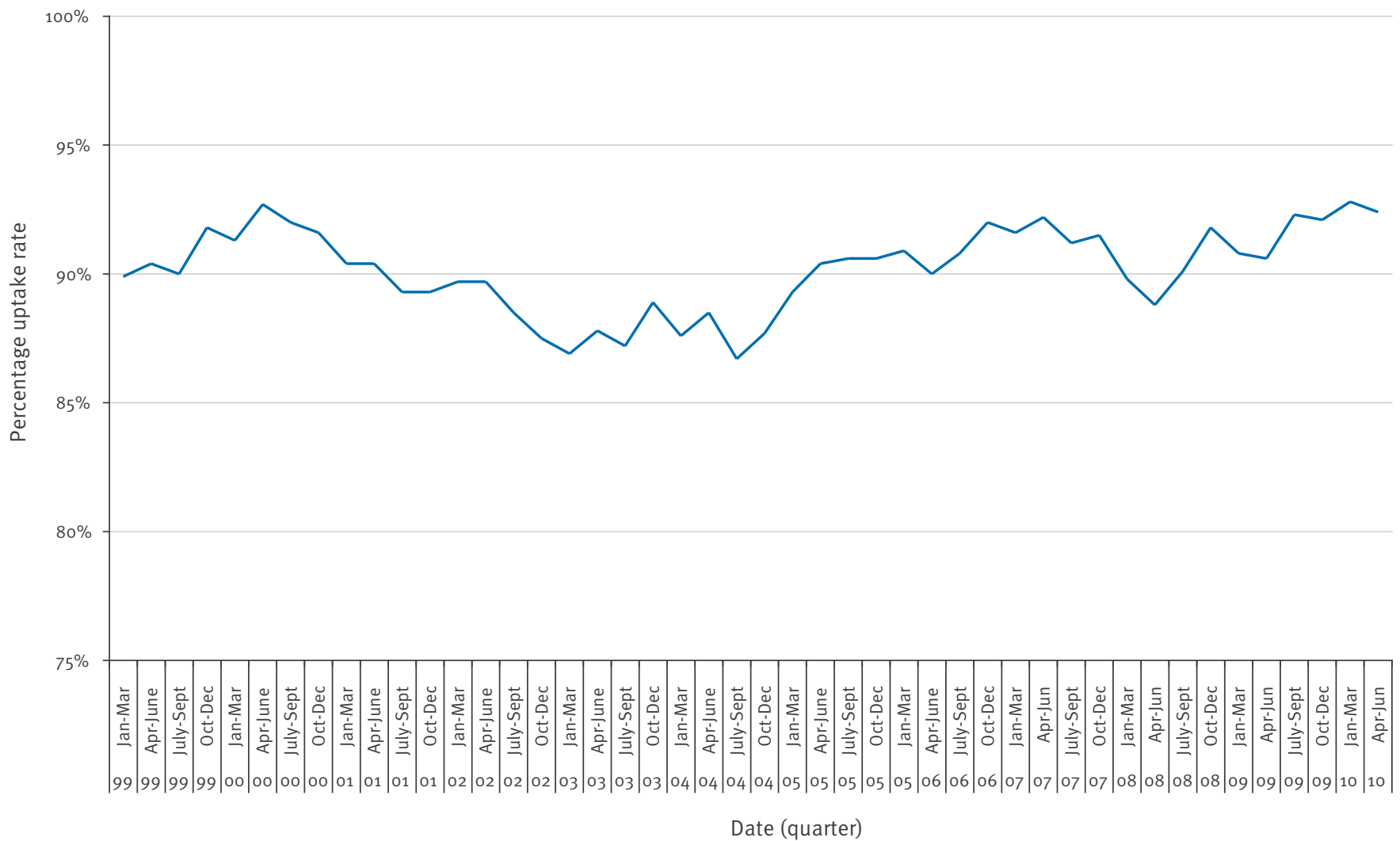

\section{FIGURE 2}

Measles-mumps-rubella vaccination uptake rate at the age of five years, Northern Ireland, 1999-2010

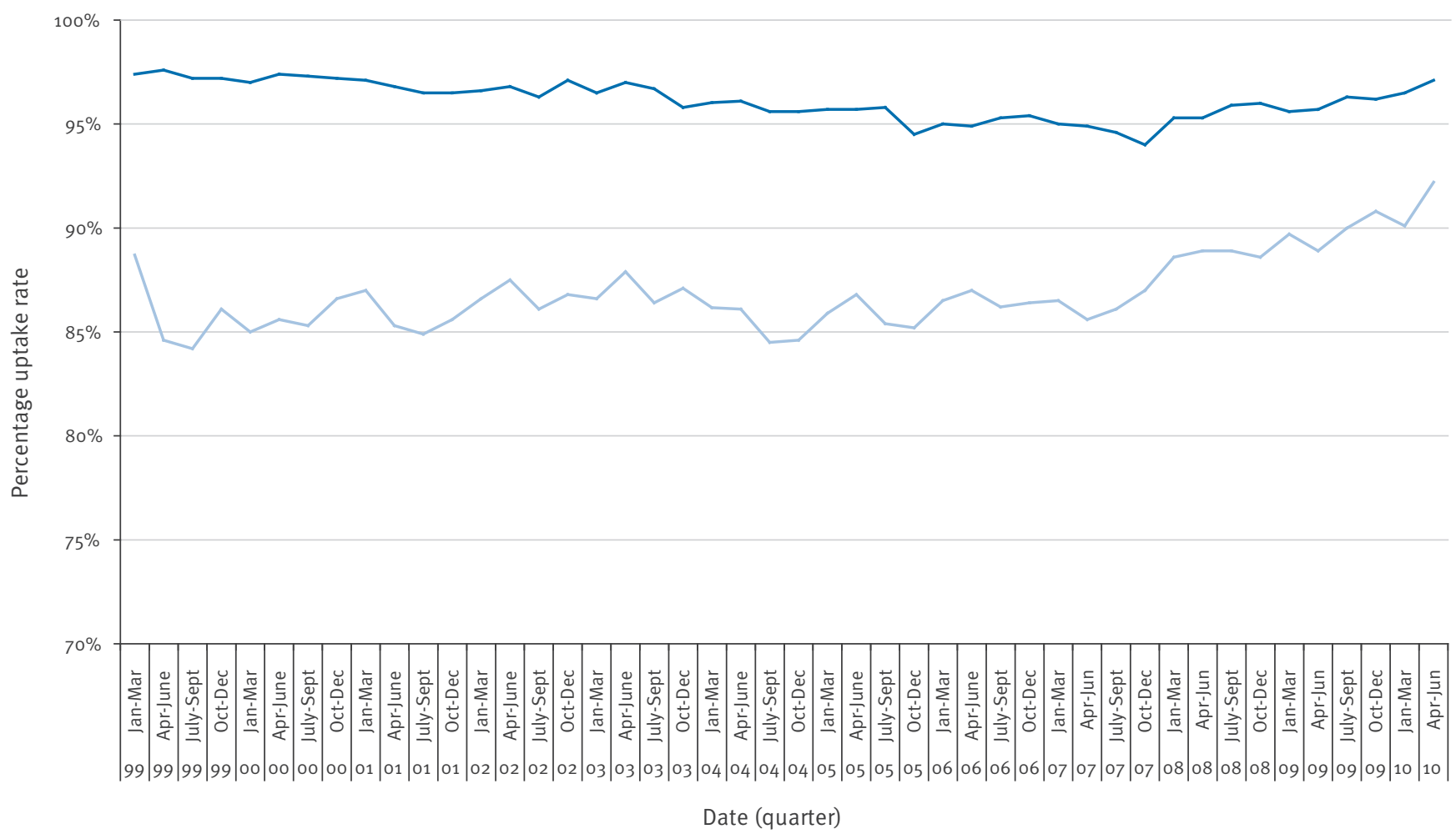


September, while infectious, at which 50-60 people were present.

At the beginning of the week starting on 11 October, a further seven cases, three of whom were laboratoryconfirmed, were reported with onsets of illness at the end of the previous week. Three cases were volunteers with the youth organisation, and four cases were siblings of the second case. All four siblings were unvaccinated against measles as were two of the volunteers. The third case, who was a laboratory-confirmed measles case, had documentary evidence of two doses of MMR vaccine, administered in 1991 and 1997. The other two cases in volunteers were a separate set of siblings. One was laboratory-confirmed, the other was not tested. Of the four siblings of the second case one was laboratory confirmed, the others were not tested.

These further seven cases attended a secondary school, a primary school, a college and a university. To date, there have been no further cases reported in any of these institutions. However, active surveillance continues.

\section{Public health actions}

Following the first case notification, the immunisation status of those in the same living accommodation was checked and all had previously received measles-containing vaccines.

On notification of the second case, a letter was sent to all the young people and staff associated with the youth organisation, in particular those who had attended the weekend event on 25-26 September. This letter advised that they should ensure they had two doses of MMR vaccine and to stay at home if they developed any of the symptoms of measles. A press release was also issued giving similar messages to the public [5].

When the further cases occurred, a letter with the same message was issued to students and staff at the four institutions involved. A second press release was issued, now highlighting that this was an outbreak and further explaining the importance of two doses of MMR vaccine [6].

A letter was also sent to general practitioners and to hospitals highlighting the importance of two doses of MMR and reinforcing the need to contact Public Health Agency should a suspected case be identified. This also signposted appropriate infection control and postexposure prophylaxis guidance $[7,8]$.

\section{Conclusion}

Recent outbreaks in countries such as Northern Ireland show that even in areas with high vaccination coverage there can be pockets of people that may be susceptible to measles infection. With current measles activity elsewhere in Europe, it is important to continue to strive to maintain and further improve MMR vaccine uptake in all European countries. It is not known whether the fully vaccinated case represents primary or secondary vaccine failure. The vaccination status of all cases will continue to be closely monitored.

\section{FIGURE 3}

Date of rash onset in laboratory-confirmed and epidemiologically linked measles cases, Northern Ireland, SeptemberOctober 2010

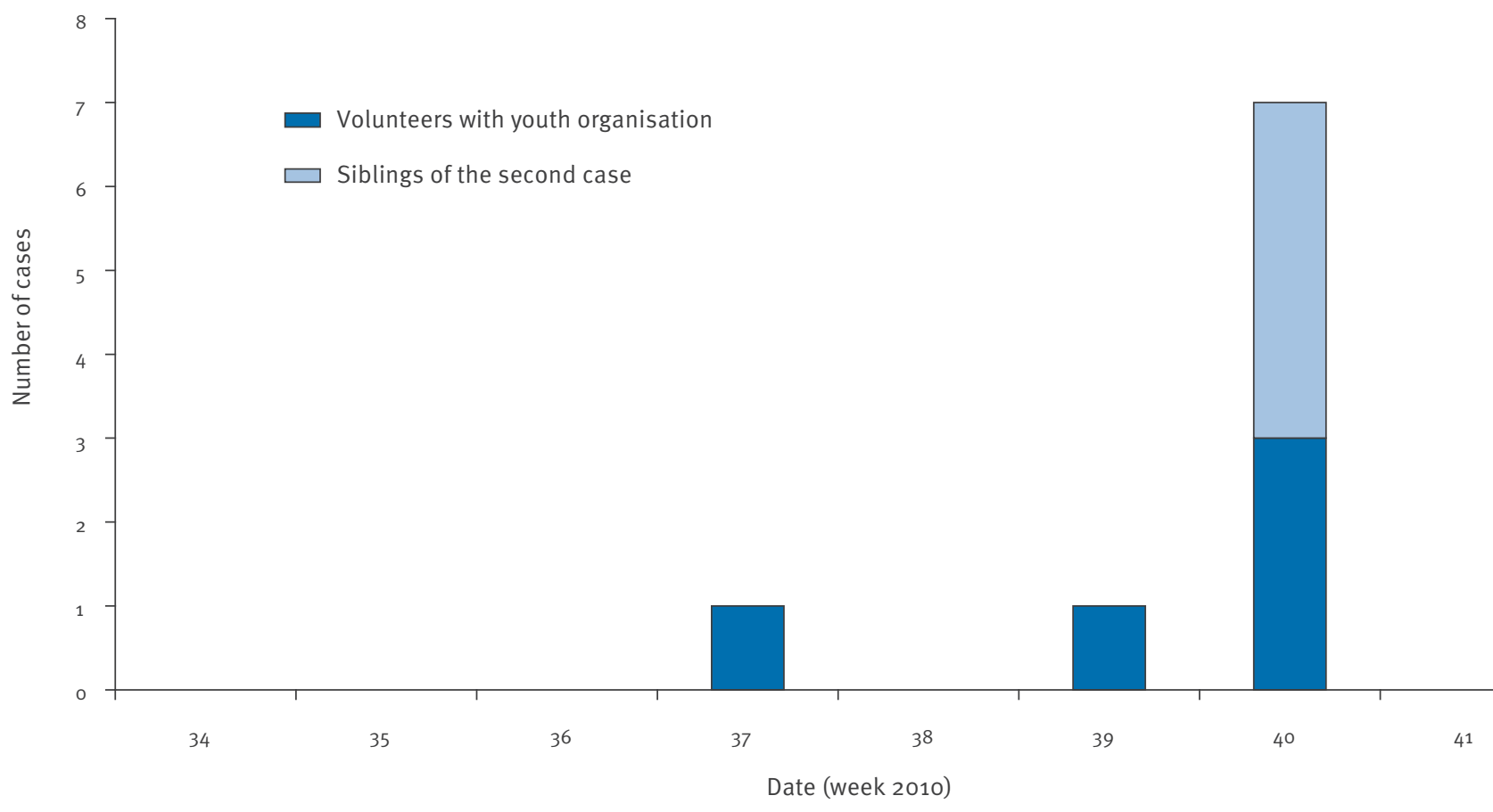




\section{References}

1. Public Health Act (Northern Ireland) 1967, Public Health Notifiable Diseases Order (Northern Ireland) 1990.

2. Public Health Agency. Communicable Disease Surveillance Centre Northern Ireland (CDSC). Vaccination Coverage Statistics for Children in Northern Ireland: Completed Primary Immunisations by 24 months. Belfast: CDSC; [Accessed $210 \mathrm{ct}$ 2010]. Available from: http://www.cdscni.org.uk/surveillance/ Coveragestats/24Months.htm

3. Public Health Agency. . Communicable Disease Surveillance Centre Northern Ireland (CDSC). Vaccination Coverage Statistics for Children in Northern Ireland: Vaccination Coverage at 5 years. Belfast: CDSC; [Accessed 21 Oct 2010]. Available from: http://www.cdscni.org.uk/surveillance/ Coveragestats/5years.htm

4. Gee S, Cotter S, O'Flanagan D, on behalf of the national incident management team. Spotlight on measles 2010: Measles outbreak in Ireland 2009-2010. Euro Surveill. 2010;15(9):pii=19500. Available from: http://www. eurosurveillance.org/ViewArticle. aspx?Articleld $=19500$

5. Public Health Agency. Children and young people must be vaccinated against measles. Belfast: Public Health Agency; [Accessed 21 Oct 2010]. Available from: http://www.publichealth.hscni.net/news/ children-and-young-people-must-be-protected-against-measles

6. Public Health Agency. Public Health Agency declares measles outbreak. Belfast: Public Health Agency; 13 Oct 2010. Available from: http://www.publichealth.hscni.net/news/ public-health-agency-declares-measles-outbreak

7. Health Protection Agency (HPA). HPA National Measles Guidelines - Local and Regional Services. HPA. 12 May 2010. Available from: http://www.hpa.org.uk/web/HPAwebFile/ HPAweb_C/1274088429847

8. Health Protection Agency (HPA). Post Exposure Prophylaxis for Measles - Revised guidance May 2009. Available from: http:// www.hpa.org.uk/web/HPAwebFile/HPAweb_C/1238565307587 